\title{
Age differences in discrimination of simulated single-formant frequency transitions
}

\author{
LOIS L. ELLIOTT, MICHAEL A. HAMMER, MARGO E. SCHOLL, and JAN M. WASOWICZ \\ Northwestern University, Evanston, Illinois
}

\begin{abstract}
We studied auditory discrimination of simulated single-formant frequency transitions that resembled portions of certain speech consonants. Significant age differences in transition discrimination occurred; both children and older adults required larger acoustic differences between transitions for discrimination than did teenagers/young adults. Longer transitions were more easily discriminated than shorter transitions by all listeners, and there were no differences between discriminations of rising and falling transitions. Teens/young adults and older adults, but not children, required larger frequency differences to discriminate frequency transitions followed by a steady-state sound than for transitions alone. There were also age differences in discrimination of steady-state sounds. These developmental-perceptual differences may help explain why children and older adults who have good pure-tone sensitivity may experience difficulty in understanding speech.
\end{abstract}

Interest in discrimination of frequency transitions (i.e., glissandi) by human listeners has been motivated by reasons as diverse as the potential relation of this discrimination to speech perception (e.g., Nabelek \& Hirsh, 1969) and the possible utilization of this skill in the design of new human-machine systems (Sergeant \& Harris, 1962). Studies that address this issue have typically used pure tones that changed in frequency, although some work has used noise bands (e.g., Collins, Cullen, Porter, \& Jackson, 1988). The listener's task has included determining whether a tone changed to a higher or lower frequency (e.g., Pollack, 1968; Sergeant \& Harris, 1962), judging which of two observation intervals contained the frequency transition (e.g., Gardner \& Wilson, 1979), or answering whether two stimuli were the "same" or "different" (e.g., Nabelek \& Hirsh, 1969). There has been no standard approach to the experimental variables manipulated; duration of the frequency transition, extent of the frequency change, and the general frequency region of the glissandi have all been investigated. To date, no work has addressed the question of how age affects the ability to discriminate frequency transitions.

Although it is known that infants can discriminate speech sounds (e.g., Eimas, Siqueland, Jusczyk, \& Vigorito, 1971; Kuhl, 1979), it has also been shown that young children require more acoustic information than do older children or young adults in order to identify highly familiar words (Elliott et al., 1979; Elliott \& Katz,

This research was supported in part by a grant from NINCDS (NIH). We thank Tom Carrell for the use of his laboratory in preparing stimuli and for comments on an earlier version of the manuscript. We are grateful to the late Jim Baker for design and construction of the computer-based equipment as well as for assistance in preparing stimuli. Requests for reprints should be sent to Lois Elliott, Program in Audiology and Hearing Impairment, Northwestern University, 2299 Sheridan Road, Evanston, IL 60208 .
1980) or to discriminate computer-synthesized speech sounds (Elliott, 1986; Elliott, Busse, Partridge, Rupert, \& DeGraaff, 1986; Elliott, Longinotti, Meyer, Raz, \& Zucker, 1981). Abundant evidence has also demonstrated that listeners over 60-65 years of age usually do not understand speech as well as do younger adults (Working Group on Speech Understanding and Aging, 1988). This occurs among those with sensitivity for pure tones within the normal range as well as for those who have developed a hearing loss.

Much speech-perception research has used consonantvowel (CV) syllables as stimuli. For example, there has been extensive study of perception of the voiced consonants associated with $/ \mathrm{ba} /-/ \mathrm{da} /-/ \mathrm{ga} /{ }^{1}$ which are differentiated perceptually, in large part, because the listener discriminates frequency transitions, or changes in "formants." Both young children (Elliott et al., 1981) and older adults (Elliott, Busse, \& Bailet, 1985) exhibit poorer discrimination of these CVs than do young adults. Because discrimination of these CVs involves discrimination of different rates of frequency change, we were interested in examining the ability of listeners of widely different ages to discriminate frequency changes that simulate the second formants of speech. Two transition durations were used because investigators have recently explored the question of whether durational modification of speech stimuli enhances identification (e.g., Gordon-Salant, 1986b). Transitions alone and transitions followed by a steady-state sound were used because, as long as three decades ago, Samoilova (1959) suggested that the greater intensity of vowel sounds exerts a masking influence on the less intense, preceding consonant sounds. Age-related differences in discrimination of steady sounds have been demonstrated (e.g., Eguchi, 1976); therefore, to allow comparison with the just noticible differences (jnds) for transitions, discrimination of steady-state sounds was also measured. 


\section{METHOD}

\section{Subjects}

Young children, teens/young adults, and older adults were recruited from the local area to serve as listeners. They participated for payment, with 16 subjects ( 8 females and 8 males) per age group. The ages were: children, 7 years 9 months to 9 years 10 months (mean $=8$ years 10 months); teens/young adults, 16 years 3 months to 21 years 3 months (mean $=18$ years 10 months); older adults, 64 years 4 months to 80 years 3 months (mean $=71$ years 7 months). All participants and parents of the children gave informed written consent.

Conventional air-conduction thresholds were obtained in both ears at octave frequencies from 500 to $2000 \mathrm{~Hz}$; all subjects selected had normal auditory sensitivity (i.e., average sensitivity at these frequencies equal to or better than $25 \mathrm{~dB}$ hearing level [ANSI, 1970]. Unless the subject preferred the left hand and used the left ear when telephoning, or unless the left ear had considerably better sensitivity than the other, the right ear was the test ear. All subjects were required to have normal middle-ear pressure (i.e., normal tympangrams) in the test ear, and none showed evidence of any other auditory pathology.

\section{Stimuli}

Computer-generated stimuli were classified according to whether they contained frequency transitions or were steady-state. All stimuli with transitions were further classified according to three characteristics: direction of the transition (rising or falling); duration of the transition $(60$ or $120 \mathrm{msec}){ }^{2}$ and whether only the transition was presented ( $T$ condition), in which case the stimulus duration equaled the transition duration, or whether the transition was followed by a steady-state sound (TS condition). All TS stimuli were $300 \mathrm{msec}$ in duration; the steady-state sound was $240 \mathrm{msec}$ in duration following 60 -msec transitions, and $180 \mathrm{msec}$ in duration after 120-msec transitions. For all TS stimuli, the center frequency of the steady-state portion was the same as the center frequency of the end of the transition; the steady-state portion was continuous with the transition (i.e., there was no temporal gap).

Ten continua, each series consisting of 13 stimuli, were generated with the Klatt (1980) parallel/cascade formant synthesizer (MIT version-KLSYN; Klatt, 1987) using all-parallel synthesis. Stimuli were generated by band-pass filtering a complex periodic source. For all stimuli, the source consisted of a series of impulses with a constant fundamental frequency (F0) of $120 \mathrm{~Hz}$. The source spectrum had a $-12 \mathrm{~dB}$ drop per octave across the harmonics of the F0. The amplinude of the source increased $60 \mathrm{~dB}$ within $5 \mathrm{msec}$ after stimulus onset, increased an additional $6 \mathrm{~dB}$ (i.e., to a maximum amplitude) in the following $10 \mathrm{msec}$, and decreased over the last $10 \mathrm{msec}$ of the stimulus. For all stimuli, a single band-pass filter with a constant $80-\mathrm{Hz}$ bandwidth was used to filter the source. The center frequency of the band-pass filter was changed at 5-msec intervals to simulate a single-formant frequency transition, or was held constant to simulate a single-formant steady state. (These stimuli will be referred to as simulated single-formant stimuli.) The digital outputs from the synthesizer (12-bit resolution; 10K sampling rate) were stored for subsequent testing. None of the stimuli sounded speechlike.

Eight continua contained stimulus transitions with filter center frequencies selected to simulate second formants of voiced stop consonants. Filter center frequencies of the four continua with rising transitions varied from 942 to $1146 \mathrm{~Hz}$ in $17-\mathrm{Hz}$ intervals, whereas filter center frequencies of the four continua with falling transitions varied from 1772 to $1340 \mathrm{~Hz}$ in $36-\mathrm{Hz}$ intervals. All transitions (both rising and falling) moved to $1240 \mathrm{~Hz}$, which was the center frequency of the steady-state portion for TS-condition stimuli. Table 1 summarizes the stimulus continua.

In the last two continua, the center frequency of the band-pass filter was held constant to simulate a single formant, 300 -msec steady state. The filter center frequencies approximately matched the midpoints of the rising or falling transitions. Thus, the ninth continuum contained steady-state stimuli with center frequencies that ranged from 1090 to $1192 \mathrm{~Hz}$ in $8.5-\mathrm{Hz}$ steps and was presented to subjects who listened to rising transitions. The 10th continuum contained center frequencies that ranged from 1505 to $1290 \mathrm{~Hz}$ in $18-\mathrm{Hz}$ steps and was presented to subjects who listened to falling transitions.

\section{Procedure}

The experiment was designed to determine the smallest acoustic differences that could be discriminated (i.e., jnds) between frequency transitions and between steady-state stimuli. On each trial, two stimuli were presented sequentially with a $500-\mathrm{msec}$ interstimulus interval. The listener's task was to judge them as "same" or "different" by pushing one of two response buttons. Trial-by-trial visual feedback was given for correct responses in the form of a smiling face.

The stimuli were presented monaurally via TDH 49 headphones at a comfortable listening level (approximately $35 \mathrm{~dB}$ sensation level). The subjects were tested individually; both the listener and the experimenter sat in a sound-treated test room.

An adaptive, simple up-down (Levitt, 1971) computer-controlled procedure was used to track the $50 \%$ correct response level for detecting stimulus differences. For example, to obtain the jnd rela-

Table 1

Characteristics of Each Stimulus Continuum

\begin{tabular}{ccccc}
\hline $\begin{array}{c}\text { Continuum } \\
\text { Number }\end{array}$ & $\begin{array}{c}\text { Direction } \\
\text { of Transition }\end{array}$ & $\begin{array}{c}\text { Duration } \\
\text { of Transition } \\
\text { (in msec) }\end{array}$ & T* or TS $\begin{array}{c}\text { Range of Onsets of } \\
\text { Filter Center } \\
\text { Frequencies } \\
\text { (in Hz) }\end{array}$ \\
\hline 1 & Rising & 60 & T & $942-1146$ \\
2 & Rising & 60 & TS & $942-1146$ \\
3 & Rising & 120 & T & $942-1146$ \\
4 & Rising & 120 & TS & $942-1146$ \\
5 & Falling & 60 & T & $1772-1340$ \\
6 & Falling & 60 & TS & $1772-1340$ \\
7 & Falling & 120 & T & $1772-1340$ \\
8 & Falling & 120 & TS & $1772-1340$ \\
9 & - & - & - & $1090-1192$ \\
10 & - & - & - & $1505-1290$ \\
\hline
\end{tabular}

Note-Stimuli of all TS continua were $300 \mathrm{msec}$ in duration; total duration of T stimuli equaled the transition duration. Stimulus Sets 9 and 10 contained $300-\mathrm{msec}$ steady-state stimuli. ${ }^{*}$ Transition-only stimuli. †Transitions followed by simulated steady-state single-formant sound. 
tive to Stimulus 1 (i.e., the "anchor") of a continuum, test trials employing Stimuli 1 and 13,12 and 1 , and 11 and 1 might be presented, and the listener might respond "different" to each pair. If Stimuli 1 and 10 were next presented, the listener might respond "same"; this constituted a "reversal" because, on the next test trial, the acoustic difference between members of a pair of test stimuli would be increased by presenting Stimuli 1 and 11. The first two reversals for test trials of each test nu were discarded, and the following eight reversals (four representing a change from decreasing stimulus differences to increasing stimulus differences and four representing the reverse) were used to calculate the jnd. Although the anchor stimulus was presented on every test trial, its position as first or second member of the pair of stimuli presented on test trials was randomly varied. The difference between the anchor stimulus and the mean of the stimuli at the reversal points was designated as " "jnd ${ }_{1}$." Just noticeable differences were always measured relative to the transition that had the smallest frequency excursion. Similarly, jnds for the steady-state sounds were measured relative to either $1192 \mathrm{~Hz}$ (for subjects who listened to rising transitions) or $1290 \mathrm{~Hz}$ (for subjects who listened to falling transitions).

In addition to the test trials, there were "catch" trials in which two identical stimuli were randomly selected from among the anchor position and the stimuli within two continuum positions of the anchor. Catch trials were inserted pseudorandomly in order to have approximately equal numbers of test and catch trials. The correct answer to catch trials was "same" and feedback was given for correct responses. Catch trials helped prevent the listener from developing a bias toward responding "different", and provided a measure of possible bias since responses to them were scored separately. The jnd, was divided by the catch-trial score, in percent correct; this value was multiplied by 100 to obtain $\mathrm{jnd}_{2}$, which was converted to frequency difference in hertz for discrimination of steadystate sounds, and to a measure of frequency change per unit of time $(\mathrm{Hz} / \mathrm{msec})$ for discrimination of transitions.

The two transition durations, the $T$ - versus TS-condition variable, and the direction of transition (rising or falling) combined to create eight experimental conditions that involved transitions. Each subject listened to half of these conditions (i.e., either rising or falling transitions). Two different orders of stimulus presentation were used. Half of the listeners in each group received two runs of each condition in the order T60, TS60, T120, TS120, and the remaining listeners were tested in the reverse order. Practice trials were given at the beginning of testing. Measures of discrimination of the steadystate stimuli were obtained at the end of testing. Data collection for each listener was completed in one session that lasted about $100 \mathrm{~min}$, with a rest break.

\section{RESULTS AND DISCUSSION}

Sixteen subjects per age group completed all procedures. Seven older adults were eliminated from the experiment for various reasons: 3 exhibited auditory sensitivity that was poorer than the $25-\mathrm{dB}$ hearing-level criterion; 2 were unable to discriminate any stimuli; 1 could not discriminate the $60-\mathrm{msec} T$ stimuli; and 1 could not discriminate the $60-\mathrm{msec} T$ or TS transitions. ${ }^{4}$

Discrimination of steady-state stimuli was evaluated in terms of jnds in hertz. There were significant age effects $[F(2,45)=9.16, p<.001]$. Post hoc tests revealed that children's discrimination of steady-state signals was poorer than that of both teens/young adults $[F(1,45)=$ $17.29, p<.001]$ and older adults $[F(1,45)=8.76$, $p<.01$ ]; there were no significant differences between discrimination of steady-state stimuli by teens/young adults and older adults (Figure 1).

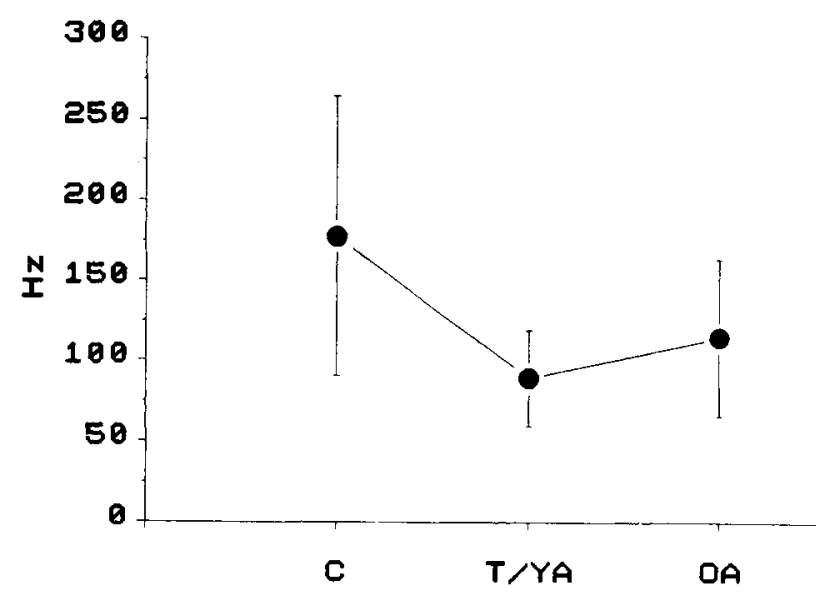

Figure 1. Auditory perceptual just noticeable differences for simulated single-formant steady-state stimuli for children $(C)$, teens/young adults (T/YA), and older adults (OA). The values represent group means $\pm S D$ (two measurements per person, 16 listeners per age group).

Discrimination of transitions was evaluated in terms of jnds expressed as the difference in rate of frequency change, or $\mathrm{Hz} / \mathrm{msec}$. A repeated measures ANOVA for jnds in differences in rate of frequency change, with transition duration and $\mathrm{T}$ versus $\mathrm{TS}$ conditions as the repeated measures and age and transition direction as betweengroup measures, was conducted (Wilkinson, 1988). Again, there was a significant age effect on performance $[F(2,42)=7.81, p<.001]$ (Figure 2). Post hoc tests revealed that both children and older adults exhibited poorer transition discrimination than did teens/young adults $^{5}$ [multivariate $F$ tests: children vs. teens/young adults, $F(4,39)=3.67, p<.02$; older adults vs. teens/young adults, $F(4,39)=3.51, p<.02$; children vs. older adults, $F(4,39)=2.11, p>.05$ ]. In addition, discrimination was significantly better for the longer transitions for all age groups $[F(1,42)=153.83, p<.001]$. (See also the discussion below of the significant interaction of age with transition only vs. transition followed by steady-state sound.) No simple ratios described the relationships between discrimination of the 60 - and $120-\mathrm{msec}$ transitions for the three ages studied (Figure 2).

There were no consistent across-age differences attributable to transition direction or to differences between $T$ and TS conditions. However, the poorer discrimination for the TS transitions among older adults and teens/young adults, and not among children, was reflected in a significant age $\times$ T versus TS interaction $[F(2,42)=4.76$, $p<.02]$.

Just noticeable differences for discrimination of steadystate sound were compared to jnds for $120-\mathrm{msec}$ transitions, with the latter evaluated as the difference in hertz at transition onsets. For the $\mathrm{T}$ condition, there was no difference between these conditions $[F(1,42)=2.53$, $p>$.05]. However, when transitions were followed by steady-state sound, there was a significant difference $[F(1,42)=13.60, p<.001]$. The jnds for teens/young adults and for older adults were poorer for the TS condi- 


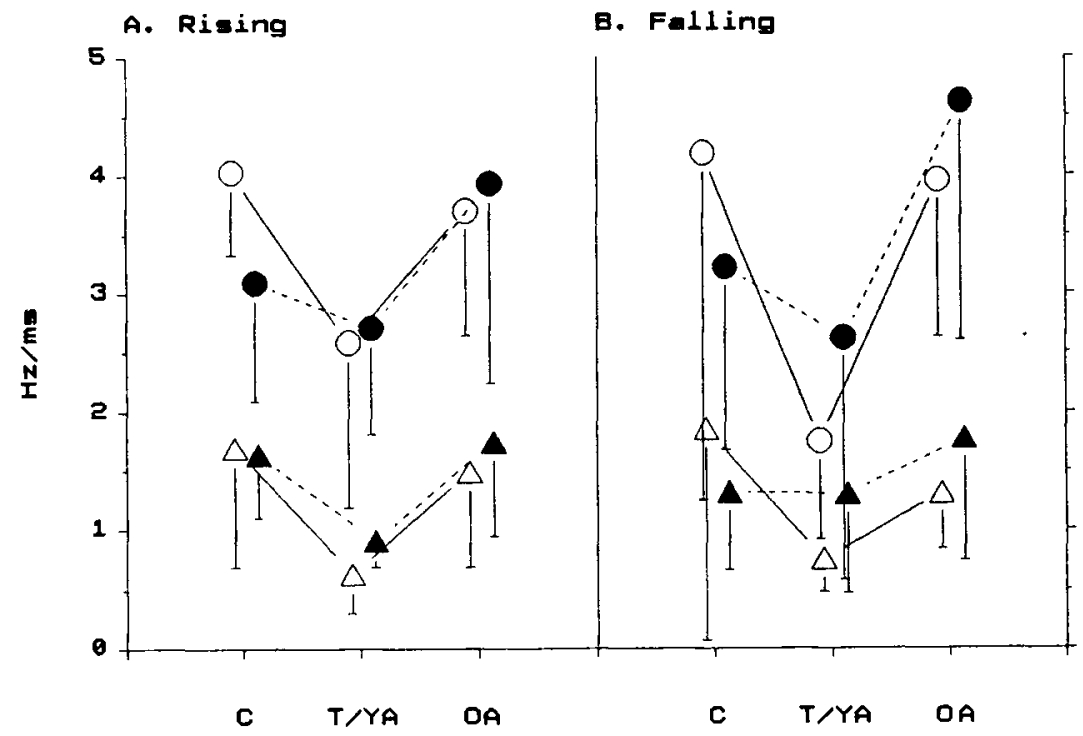

Figure 2. Auditory perceptual just noticeable differences for rising (Panel A) and falling (Panel B) transitions for children (C), teens/young adults (T/YA), and older adults (OA). Open symbols represent transition-only $(T$ conditions; filled symbols represent discrimination of transitions followed immediately by steady-state sound (TS condition). Circles represent 60-msec transitions; triangles, 120-msec transitions. The values represent group means $\pm S D$ (two measurements per person; 8 listeners per age group per panel).

tion (Figure 2) than for steady-state sound [age $\times$ stimulus condition, $F(2,42)=4.85, p<.02$ ]. In previous work, in which only young adults participated, jnds for both the 120-msec $\mathrm{T}$ and TS conditions did not differ from jnds for steady-state sound (Elliott, Hammer, Scholl, Carrell, \& Wasowicz, in press). The difference in outcomes of the two studies may have occurred, in part, because the teens/young adults of the present study exhibited (numerically) poorer performance for 120 -msec TS stimuli than for 120 -msec $T$ stimuli, but nearly equal performance in discriminating 120-msec $\mathrm{T}$ stimuli and steady-state stimuli. A possible backward-masking mechanism (see below) affecting this age group may have led to this set of outcomes.

A direct examination of performance on catch trials (in which the expected response was "same") for the steadystate stimuli provided information about the subjects' response strategies. For these stimuli, the children's average performance was $72.9 \% \pm 9.4 \%$ correct. Comparable performance for teens/young adults was $74.5 \% \pm$ $8.5 \%$ correct; for older adults, $79.6 \% \pm 12.8 \%$ correct. These values did not differ significantly. Furthermore, they did not show the V-shaped pattern that characterized jnds for discrimination of steady-state stimuli (Figure 1) or transitions (Figure 2).

Table 2 summarizes catch-trial performance for transition discrimination, collapsed over rising and falling transition conditions and focusing on transition duration and whether transitions were followed by steady-state sound. For the relatively difficult $60-\mathrm{msec}$ transitionduration conditions, average catch-trial performance of older adults and teens/young adults was nearly identical. A repeated measures ANOVA, with age as a grouping variable and the four transition conditions as repeated measures, revealed that the significant age effects obtained $[F(2,45)=6.17, p<.01]$ were attributable to differences in catch-trial performance between children and teens/young adults [multivariate tests, $F(4,42)=3.04$, $p<.05$ ]. Neither of the other two post hoc tests (teens/ young adults vs. older adults, or children vs. older adults) was statistically significant.

The catch-trial performance results suggest that young and older adult listeners addressed the task with similar strategies. There was no evidence that the older listeners adopted a stricter or a more lenient response criterion than did teens/young adults, ${ }^{6}$ as has been reported by other

Table 2

Means and Standard Deviations of Catch-Trial Performance (in Percent Correct) for Discrimination of Two Durations of

Transitions Alone (T conditions) and for Two Durations of Transitions Followed by Simulated Single-Formant Steady-State Sound (TS Conditions)

\begin{tabular}{|c|c|c|c|c|c|c|}
\hline \multirow{2}{*}{$\begin{array}{l}\text { Transition } \\
\text { Condition }\end{array}$} & \multicolumn{2}{|c|}{ Children } & \multicolumn{2}{|c|}{$\begin{array}{c}\text { Teens/Young } \\
\text { Adults } \\
\end{array}$} & \multicolumn{2}{|c|}{$\begin{array}{l}\text { Older } \\
\text { Adults }\end{array}$} \\
\hline & $M$ & $S D$ & $M$ & $S D$ & $\bar{M}$ & $S D$ \\
\hline $\mathrm{T} 60$ & 69.0 & 10.3 & 77.5 & 10.7 & 75.2 & 13.9 \\
\hline TS60 & 66.9 & 8.3 & 76.1 & 10.1 & 70.7 & 11.8 \\
\hline $\mathrm{T} 120$ & 67.7 & 15.2 & 79.8 & 7.2 & 72.7 & 13.1 \\
\hline TS120 & 71.0 & 9.3 & 82.7 & 7.8 & 77.7 & 17.1 \\
\hline
\end{tabular}

Note-T60, transition-only condition of 60-msec duration; TS60, transition followed by steady-state sound of $240-\mathrm{msec}$ duration; T120, transition-only condition of $120-\mathrm{msec}$ duration; TS120, transition followed by steady-state sound of $180-\mathrm{msec}$ duration. 
investigators (e.g., Gordon-Salant, 1986a; Rees \& Botwinick, 1971). The finding of poorest catch-trial performance by children probably indicates that they had greater difficulty in discriminating small acoustic differences than did older listeners.

The pattern of age differences that emerged resembled differences in $\mathrm{CV}$ discrimination that have been previously documented (Elliott et al., 1985; Elliott et al., 1981). That is, in the present study, young children and older adults required larger acoustic differences than did teens/young adults in order to discriminate frequency transitions, just as previous groups required larger acoustic differences to discriminate CVs that differed in the place-of-articulation feature. The finding that some elderly listeners in the present study could not discriminate some or all of the frequency transitions is reminiscent of the report by Elliott et al. (1985), in which 6 of 40 elderly subjects who could perform a syllable-identification task exhibited problems in discriminating CVs that had small acoustic differences. The present results for teens/young adults are similar to those obtained previously for young adults who received extensive practice in responding to the same stimuli (Elliott et al., in press), and resemble earlier youngadult data for discrimination of tonal transitions (Nabelek \& Hirsh, 1969). In addition, the present V-shaped agerelated functions have the same shape as results obtained in a word-identification study that used different procedures (i.e., a gating task), in which similarly-aged listeners had to identify monosyllabic words that had been standardized to be both highly familiar and highly intelligible, and which required guessing the stimulus word as well as giving a confidence rating on each trial (Elliott, Hammer, \& Evan, 1987). The relatively poorer auditory discrimination of children and older adults of the present study, compared to that of teens/young adults, appears to reflect general auditory processing by these population groups and should not be attributed either to specific features of this task or to response bias.

It does not seem appropriate to attribute these agedependent effects to the fact that listeners did not receive extensive practice before the data were collected. A definitive answer to the question of how much children's discrimination of frequency transitions would improve with practice must await direct testing. In the interim, several points may be noted. First, overall age differences in discrimination of steady-state stimuli were as large as those for discrimination of transitions, even though the former task was reported by listeners to be easier, and even though catch-trial performance for steady-state stimuli were very similar for the three age groups. In addition, the finding of the same V-shaped pattern of outcomes that was previously obtained for a quite different task that appeared not to be influenced by practice (Elliott et al., 1987) adds to the accumulating evidence that children require more acoustic information or larger acoustic differences to achieve the same performance level as young adults.

How may these age-dependent differences be explained? At least two components may be involved. Children have poorer discrimination of steady, pure tones than do young adults (Eguchi, 1976; Irwin, Stillman, \& Schade, 1986; Maxon \& Hochberg, 1982), and the same is true for older adults (e.g., Patterson, Nimmo-Smith, Weber, \& Milroy, 1982). The results of the present study for discrimination of steady-state simulated single-formant sounds numerically confirm the age-related outcomes obtained by other investigators for pure-tone discrimination. These age-related differences in discrimination of pure tones and steady-state sounds might be attributed to children and older adults having a broader auditory filter (e.g., Moore, 1982, pp. 74-106) than young-adult listeners have. When discrimination of steady sounds is diminished, it is reasonable to expect poorer discrimination of stimuli that change in frequency. However, different mechanisms for this effect may operate in the youngest and oldest groups. This possibility is suggested by the significant age $\times \mathrm{T}$ versus TS condition interaction. Teens/young adults and older adults had the poorest discrimination for the TS condition (both transition directions and durations, Figure 2), whereas children had the poorest discrimination for the $T$ condition. A mechanism such as backward masking (e.g., Elliott, 1962), produced by the steady-state sound of the TS stimuli, might be expected to interfere with transition discrimination (e.g., Collins, 1984; Collins et al., 1988). However, it is not clear why backward masking should have occurred for the two older groups of listeners and not for children. Instead, children exhibited better discrimination when the steady-state sound of the TS condition was present. This pattern of performance differences between children and the two oldest groups suggests the presence of an as yet unidentified developmental mechanism that deserves further study.

In summary, the results of this study have demonstrated that, compared to teens/young adults, children and older adults require larger acoustic differences to discriminate frequency transitions that represent important components of certain speech sounds. Children and older adults also require larger acoustic differences to discriminate steadystate simulated single-formant sounds. These resuits may help explain why some children and older adults, despite having good detection of pure tones, experience problems in understanding speech.

\section{REFERENCES}

ANSI (1970). Specifications for audiometers (S3.6-1969). New York: American National Standards Institute.

Coluns, M. J. (1984). Tone-glide discrimination: Normal and hearingimpaired listeners. Journal of Speech \& Hearing Research, 27, 403-412.

Collins, M. J., Cullen, J. K., Porter, R. J., \& Jackson, D. F. (1988). More support for rate-based discrimination of second formant transitions. Journal of the Acoustical Society of America, 83, S83-84.

EGUCHI, S. (1976). Difference limens for the formant frequencies: Normal adult values and their development in children. Joumal of the American Audiology Society, 1, 145-149.

Eimas, P. D., Siqueland, E., JusczyK, P., \& Vigorito, J. (1971). Speech perception in infants. Science, 171, 303-306.

ElLIotT, L. L. (1962). Backward masking: Monotic and dichotic conditions. Journal of the Acoustical Society of America, 34, 1108-11 15. 
Ellot T, L. L. (1986). Discrimination and response bias for CV syllables differing in voice onset time among children and adults. Journal of the Acoustical Society of America, 80, 1250-1255.

Elliott, L. L., Busse, L. A., \& Bailet, L. L. (1985). Identification and discrimination of consonant-vowel syllables by younger and older adults. Perception \& Psychophysics, 37, 307-314.

Elliott, L. L., Busse, L. A., Partridge, R., Rupert, J., \& DeGraAfF, R. (1986). Adult and child discrimination of CV syllables differing in voicing onset time. Child Development, 57, 628-635.

Elliott, L. L., Connors, S., Kille, E., Levin, S., Ball, K., \& KATZ, D. (1979). Children's understanding of monosyllabic nouns in quiet and in noise. Joumal of the Acoustical Society of America, 66, 12-21.

Elliott, L. L., Hammer, M. A., \& Evan, K. E. (1987). Perception of gated, highly familiar spoken monosyllabic nouns by children, toenagers, and older adults. Perception \& Psychophysics, 42, 150-157.

Elliott, L. L., Hammer, M. A., Scholl, M. E., Carrell, T. D., \& WAsowICZ, J. M. (in press). Discrimination of rising and falling frequency transitions: Practice and transition duration effects. Journal of the Acoustical Society of America.

Eluotr, L. L., \& KATZ, D. (1980). Northwestern University-children's perception of speech test (NU-CHIPS). St. Louis: Auditec.

Elliott, L. L., Longinotti, C., Meyer, D., RAZ, I., \& ZuCKer, K. (1981). Developmental differences in identifying and discriminating $\mathrm{CV}$ syllables. Joumal of the Acoustical Society of America, 70, 669-677.

GARDNER, R. B., \& WILSON, J. P. (1979). Evidence for direction-specific channels in the processing of frequency modulation. Journal of the Acoustical Society of America, 66, 704-709.

GoRdON-SALANT, S. (1986a). Effects of aging on response criteria in speech-recognition tasks. Joumal of Speech \& Hearing Research, 29, 155-162.

GORDON-SALANT, S. (1986b). Recognition of natural and time/intensity altered CVs by young and elderly subjects with normal hearing. Journal of the Acoustical Society of America, 80, 1599-1607.

Irwin, R. J., Stillman, J. A., \& Schade, A. (1986). The width of the auditory filter in children. Journal of Experimental Child Psychology, 41, 429-442.

KL.ATT, D. H. (1980). Software for a cascade/parallel formant synthesizer. Joumal of the Acoustical Society of America, 67, 971-995.

KLATT, D. H. (1987). KLSYN (Speech-VAX Manual, unpublished technical report). Cambridge, MA: Massachusetts Institute of Technology.

KUHL, P. K. (1979). Speech perception in early infancy: Perceptual constancy for spectrally dissimilar vowel categories. Journal of the Acoustical Society of America, 66, 1668-1679.

LEvITT, H. (1971). Transformed up-down methods in psychoacoustics. Journal of the Acoustical Society of America, 49, 467-477.

MAXON, A. B., \& HochBerg, I. (1982). Development of psychoacoustic behavior: Sensitivity and discrimination. Ear \& Hearing, 3, 301-308.

MOORE, B. C. J. (1982). An introduction to the psychology of hearing (2nd ed.). New York: Academic Press.

NABELeK, I., \& HiRSH, I. J. (1969). On the discrimination of frequency transitions. Journal of the Acoustical Society of America, 45, 1510-1519.
Patterson, R. D., Nimmo-Smith, I., Weber, D. L., \& Milroy, R. (1982). The deterioration of hearing with age: Frequency selectivity, the critical ratio, the audiogram, and speech threshold. Journal of the Acoustical Society of America, 72, 1788-1804.

PollaCK, I. (1968). Detection of rate of change of auditory frequency. Journal of Experimental Psychology, 77, 535-541.

REES, J. N. \& BoTwiNiCK, J. (1971). Detection and decision factors in auditory behavior of the elderly. Journal of Gerontology, 26, 136-139.

Samollova, I. K. (1959). Masking of short tone signals as a function of the time interval between masked and masking sounds. Biophysics, 4, 44-52.

SERGEANT, R. L., \& HARRIS, J. D. (1962). Sensitivity to non-directional frequency modulation. Journal of the Acoustical Society of America, 34, 1625-1628.

WILKINSON, L. (1988). SYSTAT: The system for statistics (Version 4.0) [Computer program]. Evanston, IL: Systat.

Working Group on SPEech Understanding and AGING. (1988). Speech understanding and aging. Journal of the Acoustical Society of America, 83, 859-895.

\section{NOTES}

1. These consonants are referred to as differing in place-of-articulation because of the position of the lips and tongue during their production.

2. The transition durations of 60 and $\mathbf{1 2 0} \mathrm{msec}$ were selected because previous research indicated that essentially no practice effects occurred for transitions of the latter duration, and limited practice effects occurred for transitions of the former duration. In contrast, extensive practice effects occurred for 30-msec transitions (Elliott et al., in press).

3. If catch trials had not been used, a listener might have discovered that a response of "different" on every test trial resulted in positive feedback.

4. Among those who completed all procedures, 2 children, 1 teen/young adult, and 1 older adult exhibited catch-trial performance of less than $40 \%$ correct for the steady-state condition; 2 children and 1 older adult had poor catch-trial performance for the T60 condition. Because this situation would have unduly influenced $\mathrm{jnd}_{2}$, the $\mathrm{jnd}_{\mathbf{2}}$ cell mean was used for these listeners.

5. The data for older adults do not include results for the 4 listeners who could not discriminate some or all of the transitions, even though they had normal hearing according to conventional audiologic pure-tone tests. Had performances of these $\mathbf{4}$ subjects been included, average results for the older adults would have been even poorer.

6. Often a more strict response criterion is interpreted as indicating greater cautiousness. It is not clear, however, that catch-trial performance may be translated directly to cautiousness; that is, it is not clear whether a higher/or lower score on catch trials would be associated with cautiousness.

(Manuscript received September 22, 1988; revision accepted for publication January 13, 1989.) 